\title{
Coactivation of Rac and Rho by Wnt/Frizzled signaling is required for vertebrate gastrulation
}

\author{
Raymond Habas, ${ }^{1,2}$ Igor B. Dawid, ${ }^{1}$ and $\mathrm{Xi} \mathrm{He}{ }^{2,3}$ \\ ${ }^{1}$ Laboratory of Molecular Genetics, National Institutes of Child Health and Human Development, Bethesda, Maryland \\ 20892-2790, USA; ${ }^{2}$ Division of Neuroscience, Children's Hospital, Department of Neurology, Harvard Medical School, \\ Boston, Massachusetts 02115, USA
}

\begin{abstract}
Wnt/Frizzled (Fz) signaling controls cell polarity/movements during vertebrate gastrulation via incompletely defined mechanisms. We demonstrated previously that Wnt/Fz activation of Rho, a GTPase and regulator of cytoskeletal architecture, is essential for vertebrate gastrulation. Here we report that in mammalian cells and Xenopus embryos, Wnt/Fz signaling coactivates Rho and Rac, another GTPase and distinct regulator of cytoskeletal architecture. Wnt/Fz activation of Rac is independent of Rho and mediates Wnt/Fz activation of Jun N-terminal kinase (JNK). Dishevelled (Dvl), a cytoplasmic protein downstream of Fz, forms a Wnt-induced complex with Rac independent of the Wnt-induced Dvl-Rho complex. Depletion or inhibition of Rac function perturbs Xenopus gastrulation without affecting Wnt/Fz activation of the Rho or $\beta$-catenin pathway. We propose that parallel activation of Rac and Rho pathways by Wnt/Fz signaling is required for cell polarity and movements during vertebrate gastrulation.
\end{abstract}

[Keywords: Wnt; Frizzled; Rac; Rho; gastrulation; vertebrates]

Received July 9, 2002; revised version accepted November 15, 2002.

Gastrulation, a complex developmental process that establishes the basic body plan, involves coordinated regulation of cell polarity, movement, and adhesion. A major driving force of this morphogenetic process in vertebrates is the so-called convergent extension $(\mathrm{CE})$ movement, in which cells polarize and elongate along the mediolateral axis and intercalate towards the midline (convergence), leading to the extension of the anterioposterior axis (extension; Shih and Keller 1992; Wallingford et al. 2002). The molecular mechanism that underlies CE movement remains to be fully understood, but recent work has revealed a key role for Wnt signaling, as disruption of Wnt-11 function perturbs CE movements in zebrafish and Xenopus (Heisenberg et al. 2000; Tada and Smith 2000).

Wnt proteins constitute a large family of secreted signaling molecules that play central roles in animal development (Wodarz and Nusse 1998). Well-studied examples of Wnt regulation of embryogenesis involve the canonical $\beta$-catenin signaling pathway, which in Xenopus induces dorsal axis formation and plays a key role in human carcinogenesis (Wodarz and Nusse 1998; Miller at al. 1999). In the Wnt/ $\beta$-catenin pathway, Wnt binding to a receptor complex composed of the serpentine Frizzled (Fz) receptor and the LRP5/6 coreceptor (Pinson

${ }^{3}$ Corresponding author.

E-MAIL xi.he@tch.harvard.edu; FAX (617) 734-1646.

Article and publication are at http://www.genesdev.org/cgi/doi/10.1101/ gad.1022203. et al. 2000; Tamai et al. 2000; Wehrli et al. 2000) activates the cytoplasmic signaling protein Dishevelled, which in turn induces the stabilization of cytosolic $\beta$-catenin, an obligatory coactivator for gene transcription (Wodarz and Nusse 1998). However, Wnt-11 control of gastrulation does not involve $\beta$-catenin but requires a distinct mechanism that shares similarity with the socalled planar cell polarity (PCP) pathway in Drosophila (Heisenberg et al. 2000, Tada and Smith 2000; Wallingford et al. 2000; Adler 2002).

PCP is manifested in Drosophila wing, eye, and sensory bristle development (Shulman et al. 1998; Adler 2002). For example, each wing cell exhibits proximaldistal polarity within the epithelial plane (hence the term PCP) by elaborating a single hair at the distal vertex pointing distally. A set of "core" PCP genes control diverse forms of planar polarity, most notably frizzled (referred to as $D f z 1)$ and dishevelled (dsh). It is believed that $\mathrm{DFz} 1 /$ Dsh and other core PCP gene products constitute a PCP "cassette" that senses polarity information in relation to major body axes (Shulman et al. 1998; Adler 2002), but whether a ligand is involved remains unresolved. Thus Fz activation is channeled via Dsh into distinct PCP and $\beta$-catenin pathways, presumably via different Dsh domains (Boutros and Mlodzik 1999). Indeed, the $d s h^{1}$ mutation is severely defective in PCP but wildtype for Wnt/ $\beta$-catenin signaling (Axelrod et al. 1998; Boutros et al. 1998).

Whereas some PCP genes show complex genetic interactions with $D f z 1$ and $d s h$ including feedback regulation 
(Mlodzik et al. 1999; Usui et al. 1999; Axelrod 2001; Strutt 2001; Adler 2002; Tree et al. 2002), rhoA and the Rho-associated kinase (Drok) represent core PCP genes that can be placed downstream of $D f z 1$ and $d s h$ (Strutt et al. 1997; Winter et al. 2001). RhoA, together with Rac and Cdc42, is a member of the Rho family of GTPases that cycle between the inactive GDP-bound form and the active GTP-bound form and regulate diverse cellular processes such as cytoskeletal dynamics, cell adhesion, cell-cycle progression, and transcription (Hall 1998; Kaibuchi et al. 1999; Van Aelst and Symons 2002). Other gene products implicated downstream of DFz1 and Dsh in PCP signaling include Rac and a MAP kinase module, JUN, JNK (JUN N-terminal kinase), and JNKK (JNK kinase; Eaton et al. 1996; Strutt et al. 1997; Boutros et al. 1998; Fanto et al. 2000), and indeed, Dsh can stimulate JNK activity in tissue culture cells (Boutros et al. 1998; Li et al. 1999; Moriguchi et al. 1999). However, the role of Rac and the JNK module in PCP signaling remains ambiguous. A triple mutation removing the three known Drosophila rac genes has no discernible PCP phenotype (Hakeda-Suzuki et al. 2002), nor do existing mutant alleles for JUN, JNK, and JNKK (Adler 2002).

In vertebrates, Wnt-11 regulation of CE movements requires the function of $\mathrm{Fz}$ and Dishevelled (Dvl), but not of $\beta$-catenin or other components involved in $\beta$-catenin signaling; furthermore, the same Dvl domains are involved in CE movements as in PCP signaling (Heisenberg et al. 2000; Tada and Smith 2000; Wallingford et al. 2000). These results imply molecular parallels between these morphogenetic events. We previously demonstrated that Wnt-11 and Wnt-1 activate RhoA via Fz/Dvl signaling, and we identified Daam1, a Formin-homology protein, as being required for $\mathrm{Wnt} / \mathrm{Fz} / \mathrm{Dvl}$ activation of RhoA, Wnt-induced Dvl-RhoA complex formation, and CE movements during Xenopus gastrulation (Habas et al. 2001). Further supporting the notion of conservation of the PCP pathway, the vertebrate homolog of strabismus, a core PCP gene encoding a multispan transmembrane protein (Wolff and Rubin 1998), is required for gastrulation in Xenopus and zebrafish (Darken et al. 2002; Goto and Keller 2002; Jessen et al. 2002; Park and Moon 2002). Interestingly, Xenopus Strabismus protein can activate JNK (Park and Moon 2002), and depletion of Xenopus JNK causes defective gastrulation (Yamanaka et al. 2002). These results suggest that JNK is a component of PCP signaling in vertebrates, and raise questions about the relationships among JNK, Rac, and the Wnt/Fz/Dvl/ Rho pathway.

Here we report that Wnt/Fz signaling induces Rac and Rho activation during Xenopus gastrulation. Rac activation is independent of Wnt/Fz-triggered Rho activation, and mediates Wnt/Fz/Dvl activation of JNK. Wnt signaling induces the formation of a Dvl-Rac complex that is independent of the Wnt-induced Dvl-Rho complex. Depletion of or interference with Rac function in Xenopus embryos inhibits CE movements and gastrulation. We propose that parallel activation of both Rac and Rho underlies Wnt regulation of vertebrate morphogenesis.

\section{Results}

Wnt/Fz signaling activates Rac

For detection of Wnt/Fz activation of Rho, Rac, and Cdc42 we used an established biochemical assay (Habas et al. 2001), which employs GST-RBD (Rho binding domain, fused with the glutathione S-transferase) fusion protein that recognizes GTP-bound $\overline{\mathrm{R}}$ ho (Ren et al. 1999), and GST-PBD (p21 binding domain) that recognizes GTP-bound Rac and Cdc42 (Ak kasaki et al. 1999; Benard et al. 1999). We found previously that Wnt/Fz signaling activates Rho but not Cdc42 in human 293T cells (Habas et al. 2001), whereas data on Rac activation were less clear due to high basal levels of activated Rac. We subsequently found that low basal Rac activation could be achieved by lowering the serum concentration in the medium (see Materials and Methods). Under these conditions, expression of certain Fz cDNAs resulted in significant Rac activation that paralleled Rho activation in a Fz-specific fashion (Fig. 1A). Thus Fz7, which has been implicated in vertebrate gastrulation and $\beta$-catenin signaling (Djiane et al. 2000; Medina et al. 2000; Sumanas et al. 2000), activated both Rac (Fig. 1A) and Rho (Habas et al. 2001). Similarly, Fz1 activated both Rac (Fig. 1A) and Rho (Habas et al. 2001) in addition to $\beta$-catenin signaling (Yang-Snyder et al. 1996). Fz2 and Fz5 exhibited weak or no activation of Rac (Fig. 1A) or Rho (Habas et al. 2001), although Fz5 can induce $\beta$-catenin signaling (He et al. 1997), and Fz2 engages a $\mathrm{Ca}^{2+} /$ protein kinase $\mathrm{C}$ pathway (Sheldahl et al. 1999). As a positive control, Ephexin, a guanine nucleotide exchange factor (GEF) for Rac, Rho, and Cdc42 (Shamah et al. 2001), activated all three GTPases (Fig. 1A; Habas et al. 2001).

We further tested whether Wnt signaling regulates Rac. Addition of Wnt-1 conditioned media (CM) to 293T cells resulted in rapid Rac activation that was observable within $5 \mathrm{~min}$ and lasted for at least $3 \mathrm{~h}$ (Fig. 1B). Wnt-1 CM activation of Rac was not blocked (but slightly enhanced) by cycloheximide, a protein synthesis inhibitor (Fig. 1B), suggesting that Rac lies directly downstream of Wnt signaling. We previously observed that Wnt-1 activation of Rho is insensitive to cycloheximide treatment but occurs with a slower time course, being observable within 30 min of Wnt-1 treatment (Habas et al. 2001).

\section{Wnt/Fz/Dvl signaling activates Rac and Rho in parallel pathways}

Dsh/Dvl proteins function downstream of $\mathrm{Fz}$ in the activation of both $\beta$-catenin and Rho pathways (Boutros and Mlodzik 1999; Habas et al. 2001). We tested whether Dsh/Dvl proteins activate Rac. Mouse Dishevelled 1 and 2 (Dvl1 and Dvl2), but not mouse Dvl3, and Xenopus and Drosophila Dishevelled (Xdsh and Dsh) activated Rac (Fig. 1C). Rho activation by these Dvl/Dsh proteins exhibited similar patterns (data not shown). Dsh/Dvl proteins have three conserved domains (Boutros and Mlodzik 1999): the N-terminal DIX domain is essential for $\beta$-catenin signaling but not for $\mathrm{PCP} /$ Rho activation, and the central PDZ and C-terminal DEP domains are 

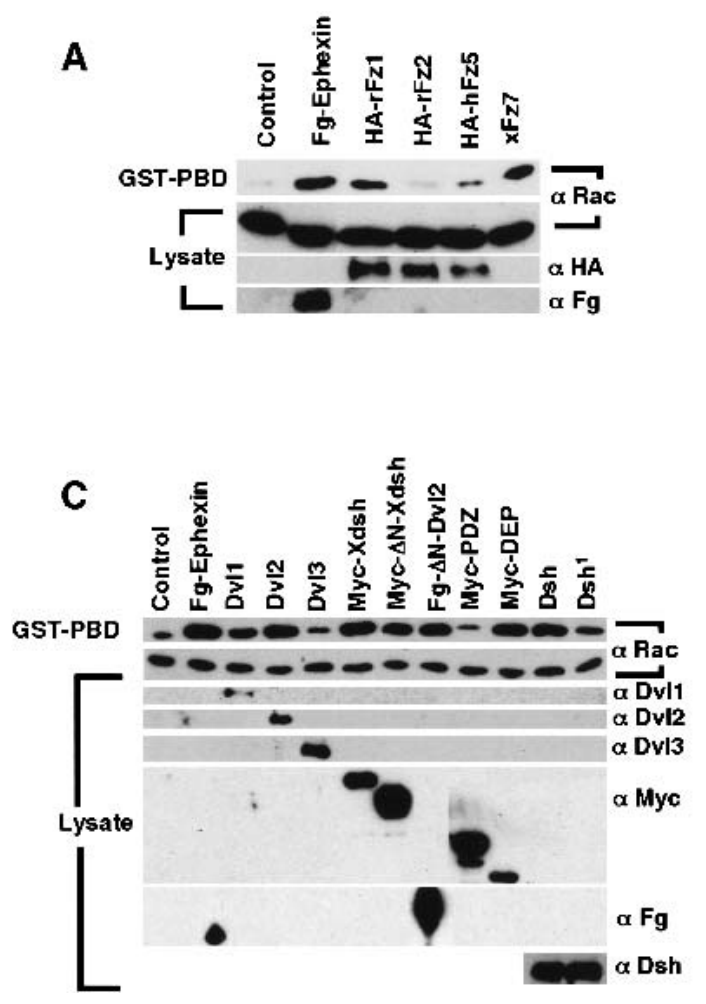
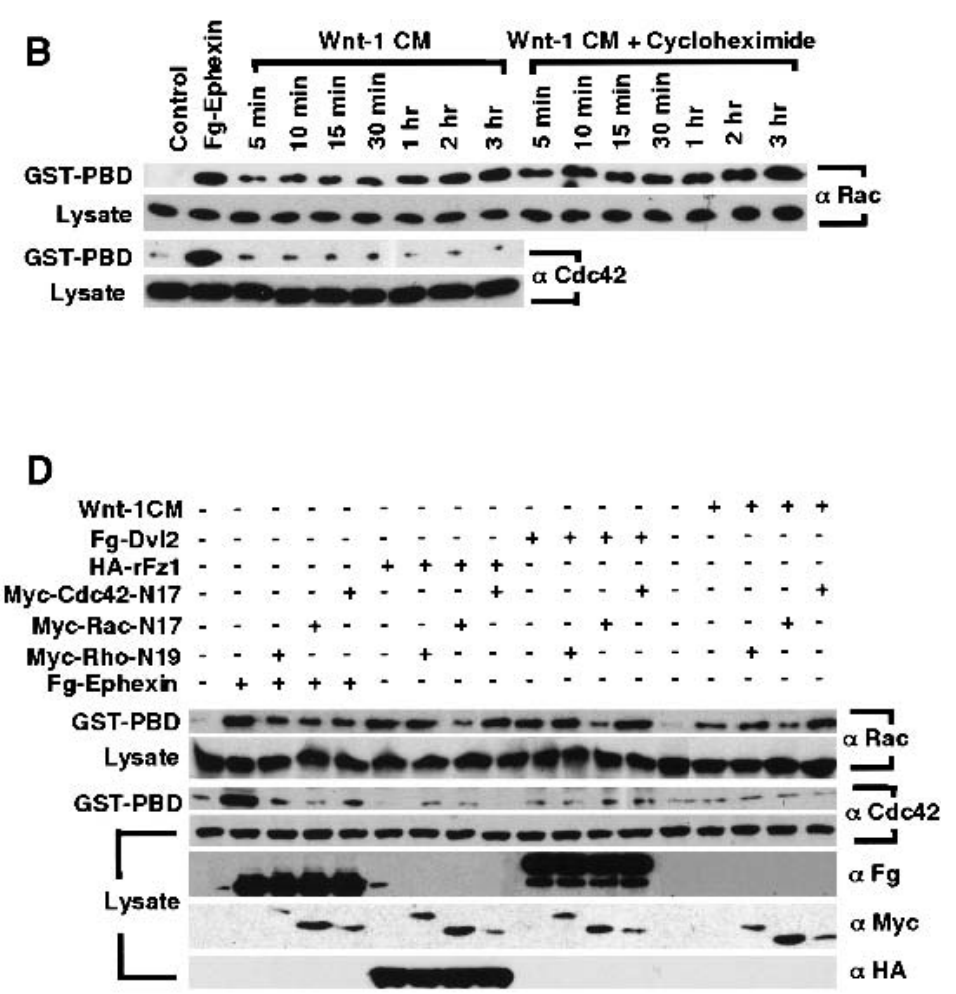

Figure 1. Wnt/Fz/Dvl signaling activates Rac and Rho in parallel pathways. $(A)$ Rac activation by specific Fz proteins. Fzl (rat) and Fz7 (Xenopus) activated Rac, but Fz2 (rat) or Fz5 (human) did not (the slight Rac activation seen in the Fz5 lane was not reproducible). (B) Rac activation by Wnt-1 CM was rapid (5 min) and lasting $(3 \mathrm{~h})$, and resistant to cycloheximide treatment (which inhibited cyclin D1 induction by Wnt-1 CM, data not shown). Cdc42 was not activated by Wnt-1 CM. (C) Rac activation by Dvl1 and Dvl2, but not Dvl3; by Xdsh and Dsh; by Dvl2 and Xdsh mutants lacking the DIX domain ( $\Delta \mathrm{N}-\mathrm{Dvl2}$ and $\Delta \mathrm{N}-\mathrm{Xdsh})$; and by the DEP domain but not the PDZ domain alone. The Dsh ${ }^{1}$ mutant had weaker activity than Dsh in Rac activation. (D) Rac-N17, but neither Rho-N19 nor Cdc42-N17, inhibited Rac activation by Wnt-1 CM, Fz1, or Dvl2. Rac-N17, Rho-N19, and Cdc42-N17 each inhibited Ephexin activation of Rac and Cdc42 (and Rho; Habas et al. 2001).

both required for the PCP function and Rho activation (Axelrod et al. 1998; Boutros et al. 1998; Heisenberg et al. 2000; Tada and Smith 2000; Wallingford et al. 2000; Habas et al. 2001). Consistent with these conclusions, we find that the DIX domain is not critical for Rac activation, because Dvl2 and Xdsh mutants lacking the DIX domain ( $\Delta$ N-Dvl2 and $\Delta$ N-Xdsh) activated Rac (Fig. 1C). Further, the DEP domain alone activated Rac to levels similar to wild-type Dvl2, whereas the PDZ domain alone did not (Fig. 1C). The significance of the DEP domain in Rac activation was also illustrated by $\mathrm{Dsh}^{1} \mathrm{mu}-$ tant, which harbors a missense mutation in the DEP domain and is defective in PCP but not $\beta$-catenin signaling (Axelrod et al. 1998; Boutros et al. 1998). Compared to wild-type Dsh, the Dsh ${ }^{1}$ mutant exhibited reduced Rac activation (Fig. 1C). Because the DEP domain alone fully activates Rac but not Rho, Rac and Rho activation by Dsh/Dvl likely occurs independently.

Like other GTPases, Rac, Rho, and Cdc42 require specific GEFs for their activation (Kaibuchi et al. 1999; Schmidt and Hall 2002), and dominant interfering forms, such as Rho-N19, Rac-N17, and Cdc42-N17 can bind and titrate specific GEFs in certain instances, thereby blocking the activation of the wild-type factors (Hart et al.
1994). As shown in Figure 1D, only Rac-N17, but not Rho-N19 or Cdc42-N17, inhibited Rac activation in 293T cells by Wnt-1 CM, Fz1, or Dvl2. We previously showed that Rho-N19, but not Rac-N17 or Cdc42-N17, inhibits Rho activation in these cells by Wnt-1, Fz1, or Dvl2 (Habas et al. 2001). These results demonstrate the specificity of Rac-N17 and Rho-N19 under our experimental conditions, and further suggest that Wnt/Fz/Dvl activation of Rac and Rho occurs independently and may require a distinct Rac-GEF and Rho-GEF, respectively. For comparison, Rac-N17, Rho-N19, and Cdc42-N17 each inhibited Ephexin activation of Rho (Habas et al. 2001), Rac, and Cdc42 (Fig. 1D), consistent with the notion that Ephexin is a multifunctional GEF for all three GTPases (Shamah et al. 2001).

\section{Wnt/Fz/Dishevelled activation of JNK is mediated by Rac}

As the Dvl DEP domain is sufficient for JNK activation (Boutros et al. 1998; Li et al. 1999; Moriguchi et al. 1999), and can activate Rac but not Rho (Fig. 1C; Habas et al. 2001), JNK may be activated downstream of Rac but not of Rho in Wnt/Fz signaling. We first examined whether 
Habas et al.

Fz proteins can activate JNK. JNK activation was assayed via monitoring c-Jun phosphorylation using a phosphoJun-specific antibody (Boutros et al. 1998; Sun et al. 2001; Park and Moon 2002). We observed that Fz1 and Fz7, but not Fz2 or Fz5, activated JNK (Fig. 2A), in correlation with the activation of Rac (Fig. 1A) and Rho (Habas et al. 2001) by these factors. It was reported that XWnt-5a and XFz8 can induce JNK activation (Lisovsky et al. 2002; Yamanaka et al. 2002). Wnt-1 CM stimulation of $293 \mathrm{~T}$ cells also resulted in a rapid JNK activation, which was insensitive to cycloheximide and detectable within 5 min of Wnt-1 CM addition (Fig. 2B) and was thus detectable together with Rac activation but prior to Rho activation by Wnt-1.

Expression of Dvl1 and 2, Xdsh and Dsh, but not Dvl3, activated JNK (Fig. 2C). Consistent with previous findings (Boutros et al. 1998), the Dsh ${ }^{1}$ mutant exhibited weaker activity in JNK activation, whereas Dvl2 and Xdsh mutants lacking the DIX domain, $\Delta \mathrm{N}$-Dvl2 and $\Delta \mathrm{N}$-Xdsh, activated JNK effectively (Fig. 2C); the DEP domain alone, but not the PDZ domain, also activated JNK (Fig. 2C). Thus, a full correlation between JNK and Rac, but not Rho, activation was observed. Further, RacN17, but not Rho-N19 or Cdc42-N17, inhibited JNK activation by Wnt-1, Fz1, and Dvl2 (Fig. 2D-F). Taken together, these observations demonstrate that activation of Rac, but not of Rho, mediates Wnt/Fz/Dvl activation of JNK.

\section{Wht induction of a Dvl-Rac complex}

We previously observed a Wnt-induced Dvl-RhoA complex, whose formation correlates with Wnt/Fz/Dvl activation of RhoA (Habas et al. 2001). We thus examined whether Wnt activation of Rac is accompanied by the formation of a Dvl-Rac complex. Immunoprecipitation of endogenous Rac protein from 293T cells revealed Dv12 protein in Rac immunoprecipitates in Wnt-treated cells (Fig. 3A). Likewise, immunoprecipitation of RhoA but not Cdc42 also coprecipitated Dvl2 in Wnt-stimulated cells (Fig. 3A). These results suggest that Wnt signaling
A

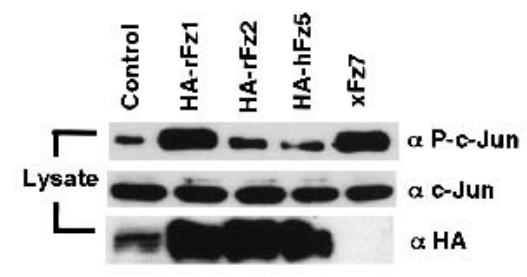

B
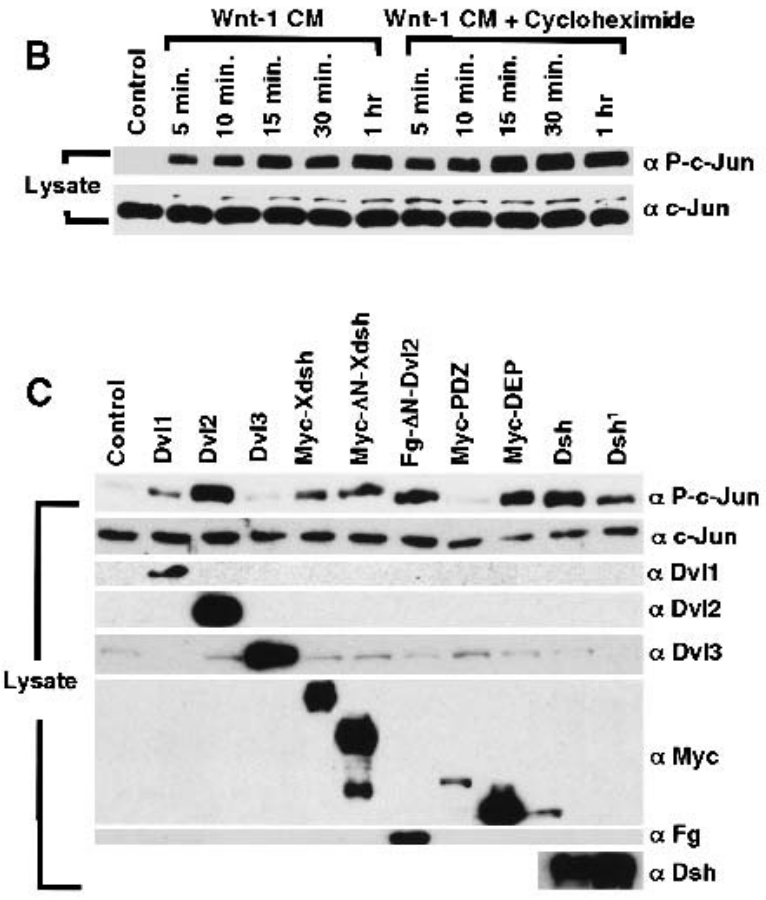

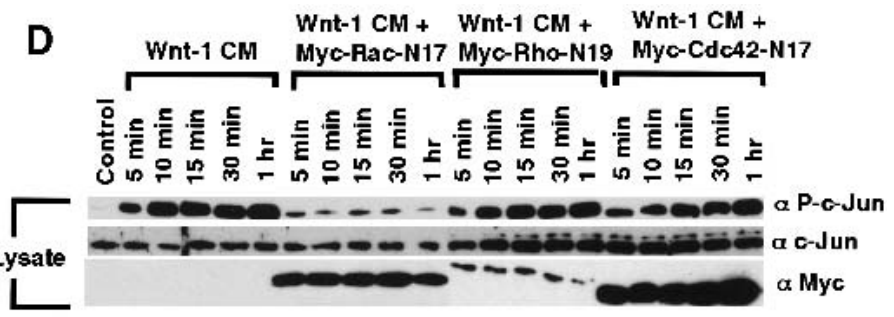

E

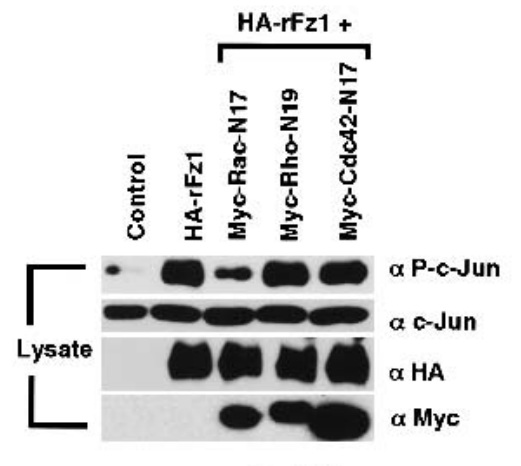

$\mathbf{F}$

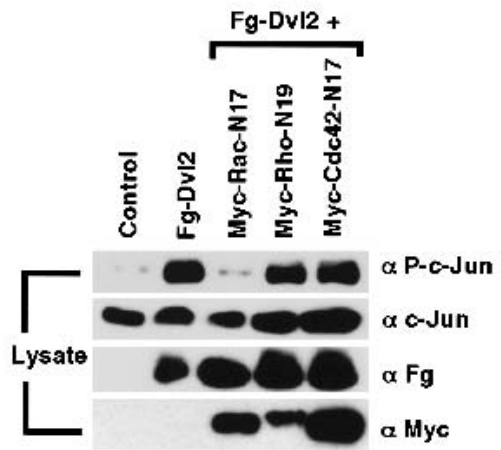

Figure 2. Wnt/Fz/Dvl activation of JNK via Rac but not Rho. (A) JNK activation by specific Fz proteins. Fz1 and Fz7 activated JNK, but Fz2 or Fz5 did not or did weakly. (B) Wnt-1 CM, but not control CM, activated JNK rapidly in the presence of cycloheximide. $(C)$ JNK activation by Dvl1 and Dvl2, but not Dvl3; by Xdsh and Dsh; by Dvl2 and Xdsh mutants lacking the DIX domain ( $\Delta$ N-Dvl2 and $\Delta \mathrm{N}$-Xdsh); and by the DEP domain but not the PDZ domain alone. The Dsh ${ }^{1}$ mutant had weaker activity than Dsh in JNK activation. $(D-F)$ JNK activation by Wnt-1 CM $(D)$, or by transfected Fz1 $(E)$ or Dvl2 $(F)$ was blocked by Rac-N17 but not Rho-N19 or Cde42-N17. 

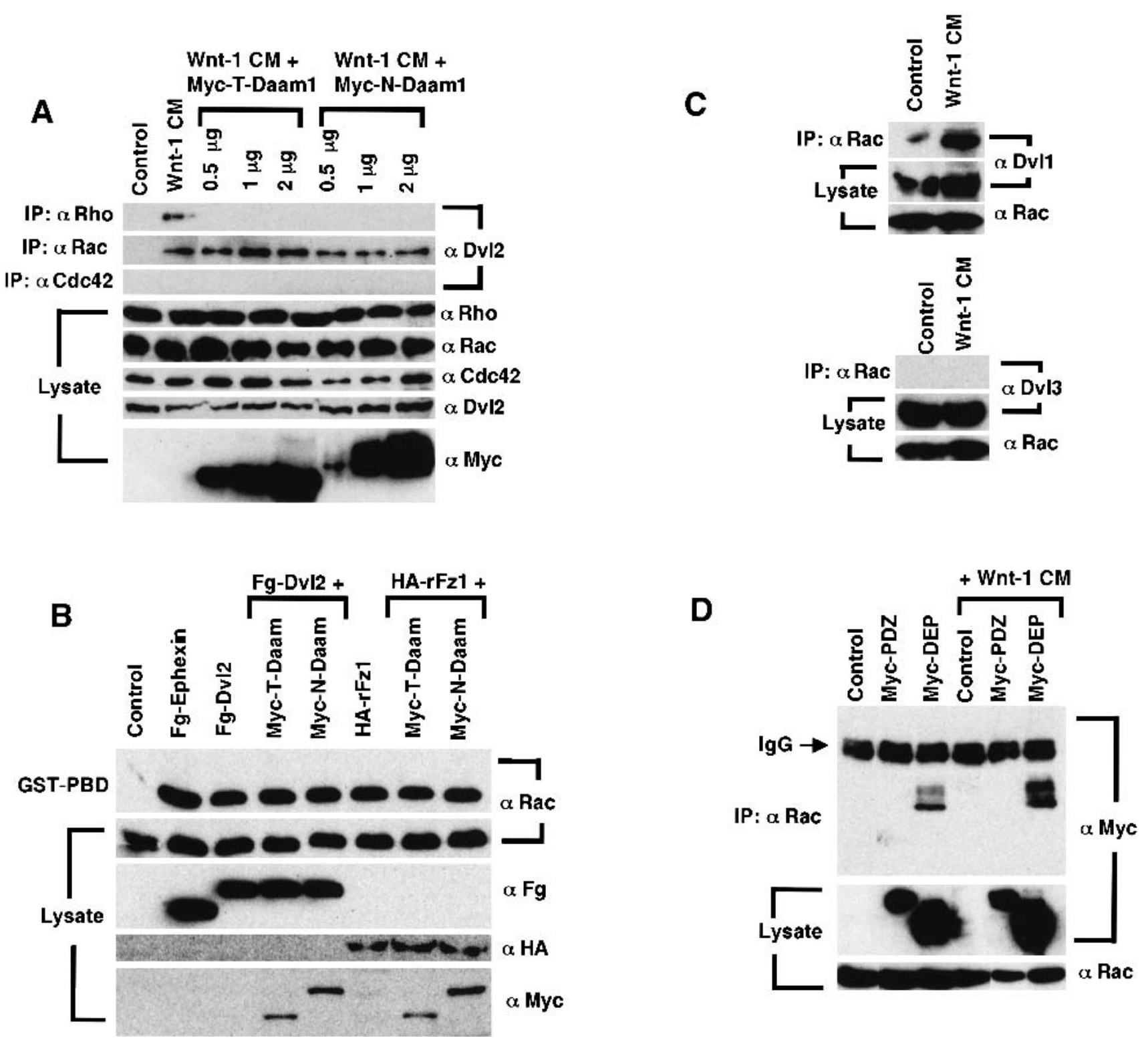

Figure 3. A Wnt-induced Dvl-Rac complex that is independent of the Wnt-induced Dvl-Rho complex. $(A)$ Wnt-1 CM induced formation of a complex between Dvl2 and Rac or Rho, but not Cdc42. T-Daam1 or N-Daam1 disrupted the Dvl2-Rho complex but not the Dvl2-Rac complex. Endogenous Rac, Rho, or Cdc42 was immunoprecipitated from cells treated with/without Wnt-1 CM for 3 h, and coprecipitated endogenous Dvl2 was detected by immunoblotting. (B) Rac activation by Fz1 or Dvl2 was not inhibited by T-Daam1 or N-Daam 1. (C) Wnt-1 CM induced a complex formation between endogenous Rac and Dvl1, but not Dvl3. (D) The Dvl2 DEP domain, but not the PDZ domain, formed a complex with Rac with or without Wnt-1 stimulation.

results in the formation of a Dvl-Rac complex in addition to the Dvl-Rho complex. Dvl-Rho complex formation requires the Formin-homology protein Daam1, and thus is disrupted by either N-Daam 1 , an N-terminal fragment that binds Rho, or T-Daam1, a C-terminal fragment that binds Dvl (Fig. 3A; Habas et al. 2001). However, Wnt-induced Dvl-Rac complex formation was not affected by N-Daam1 or T-Daam1, and thus does not require Daam1 function. Further, although N-Daam1 and T-Daam 1 each inhibit Rho activation by Wnt, Fz, or Dvl (Habas et al. 2001), they did not affect Rac activation by Dvl2 or Fzl (Fig. 3B), demonstrating again that Wnt/ Fz signaling activates Rac and Rho independently.

Endogenous Dvl1, but not Dvl3, was also detected in Rac immunoprecipitates of Wnt-1-stimulated cells (Fig. 3C), mirroring their roles in Rac activation (Fig. 1C). Further, the Dvl2 DEP domain, but not the PDZ domain, associated with Rac with or without Wnt stimulation (Fig. 3D), consistent with the finding that the DEP domain alone activated Rac (Fig. 1C). Thus, Dvl-Rac complex formation correlates fully with Rac activation in Wnt/Fz signaling. 
Dorsal Rac activation by Wnt/Fz signaling in Xenopus gastrulation

Our biochemical studies demonstrated a Wnt/Fz/Dvl/ Rac/JNK signaling pathway in mammalian cells. Given that Wnt-11/Fz signaling and JNK function are involved in CE movements during vertebrate gastrulation (Diiane et al. 2000; Heisenberg et al. 2000; Tada and Smith 2000; Yamanaka et al. 2002), we sought to determine whether Wnt-11/Fz regulation of Xenopus gastrulation involves Rac activation. We searched sequence data bases and found a Xenopus Rac gene, which shares $92 \%$ amino acid sequence identity with human, rat, mouse, and Drosophila Rac1, and was thus named Xenopus Rac1 (XRac1). XRac1 is expressed maternally and throughout embryogenesis as determined by RT-PCR (Fig. 4A). The identical XRac1 sequence was recently reported (Lucas et al. 2002).

CE movements are a major driving force of Xenopus gastrulation and occur predominantly on the dorsal side of the embryo (Shih and Keller 1992), where Wnt-11/Fz signaling is active (Wallingford et al. 2002). Endogenous Rac protein was detected in equal amounts in dorsal and ventral marginal zone explants (DMZ vs. VMZ), but activated Rac was detected mainly in the DMZ (Fig. 4B). Cdc42 activation was not observed in either DMZ or VMZ under these conditions (Fig. 4B). Dorsal Rac activation depends on Wnt-11/Fz signaling, because it was

A
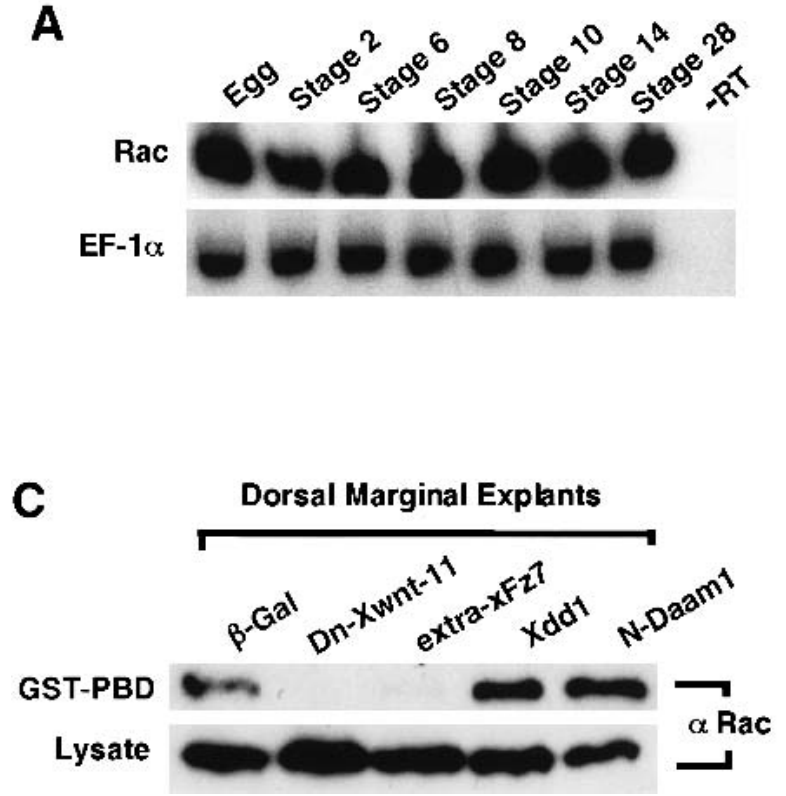

blocked by the dominant negative XWnt-11 and xFz7 mutants, Dn-Xwnt-11 and extra-Fz7 (Fig. 4C), which prevent CE movements in Xenopus embryos (Djiane et al. 2000; Tada and Smith 2000). Conversely, Rac was activated upon ectopic Wnt-11, Fz7, or Xdsh signaling in the VMZ (Fig. 4D). Thus, Wnt-11/Fz signaling is necessary and sufficient for Rac activation. Although Rho activation also occurs on the dorsal side due to Wnt-11/Fz signaling in Xenopus embryos (Habas et al. 2001), important distinctions were observed between Rac and Rho activation. Xdd1, which is a Xdsh mutant lacking part of the PDZ domain, blocks dorsal Rho activation (Habas et al. 2001) but enhanced dorsal Rac activation (Fig. 4C) and induced ventral Rac activation (Fig. 4D). This is consistent with the observation that the DEP domain alone is sufficient for Rac activation, whereas both PDZ and DEP domains are required for Rho activation (Fig. 1C; Habas et al. 2001). We previously showed that Daam 1 is required for Wnt-11/Fz/Dvl activation of Rho in Xenopus (Habas et al. 2001). N-Daam1, which blocks Rho activation by Wnt-11/Fz in the DMZ (Habas et al. 2001), did not block dorsal Rac activation (Fig. 4C). C-Daam1, a constitutively activated mutant that induces Rho activation in the VMZ (Habas et al. 2001), failed to activate Rac (Fig. 4D). These results demonstrate that, as in mammalian cells, Wnt-11/Fz/Dvl signaling during Xenopus gastrulation induces coactivation of Rac and Rho via independent pathways.

Figure 4. Dorsal Rac activation by Wnt-11/Fz signaling during Xenopus gastrulation. $(A)$ XRac1 RNA is expressed maternally and throughout embryogenesis as monitored by RT-PCR. EF- $1 \alpha$ was used as a loading control. $-\mathrm{RT}$, without reverse transcriptase. $(B)$ Endogenous Rac activation was detected in DMZ but not in VMZ isolated from stage 10.5 embryos. Cdc42 activation was not detected in DMZ or VMZ. $(C)$ Endogenous Rac activation was inhibited in DMZ by injected RNA for Dn-Xwnt-11 (1 ng) or extra-xFz7 (1 ng). RNA for Xdd1 (1 ng) or N-Daam1 ( $2 \mathrm{ng})$ did not inhibit dorsal Rac activation. $\beta$-galactosidase RNA ( $\beta$-gal, $2 \mathrm{ng}$ ) injection was used as control. (D) Rac was ectopically activated in VMZ by RNA for Xwnt-11 (200 pg), xFz7 (200 pg), Xdsh (1 ng), or Xdd1 (1 ng), but not by C-Daam1 DNA (200 pg) or by $\beta$-gal RNA ( $2 \mathrm{ng}$ ). C-Daam1 DNA was injected instead of RNA, which interfered with early embryo cleavage (Habas et al. 2001). 
Rac function is required for Xenopus gastrulation

To investigate the role of Rac during Xenopus embryogenesis, we attempted to deplete XRac1 via a morpholino antisense oligonucleotide (MO), which was designed to block the translation of the endogenous XRac1 protein. Injection of the XRac1 MO reduced the endogenous Rac, but not Rho or Cdc42, protein level, whereas an unrelated control MO had no effect (Fig. 5A).

Embryos injected dorsally with the XRacl MO developed normally during cleavage (data not shown), but a significant portion exhibited gastrulation abnormalities including a large and open blastopore, shortened body axis, and microcephaly (Fig. 5B; Table 1). These phenotypes are characteristic of defects in morphogenetic movements (Diiane et al. 2000; Tada and Smith 2000; Wallingford et al. 2000). Importantly, the gastrulation abnormalities resulting from the XRac1 MO could be rescued by coinjection of human Racl RNA (whose translation was resistant to XRacl MO inhibition), but not by human RhoA or Cdc42 RNA (Fig. 5B; Table 1). Control MO injected dorsally, or XRacl MO injected ventrally, had no effect on Xenopus development (Table 1; data not shown).

Many embryos injected dorsally with the XRac1 MO nonetheless developed normally (Table 1), presumably
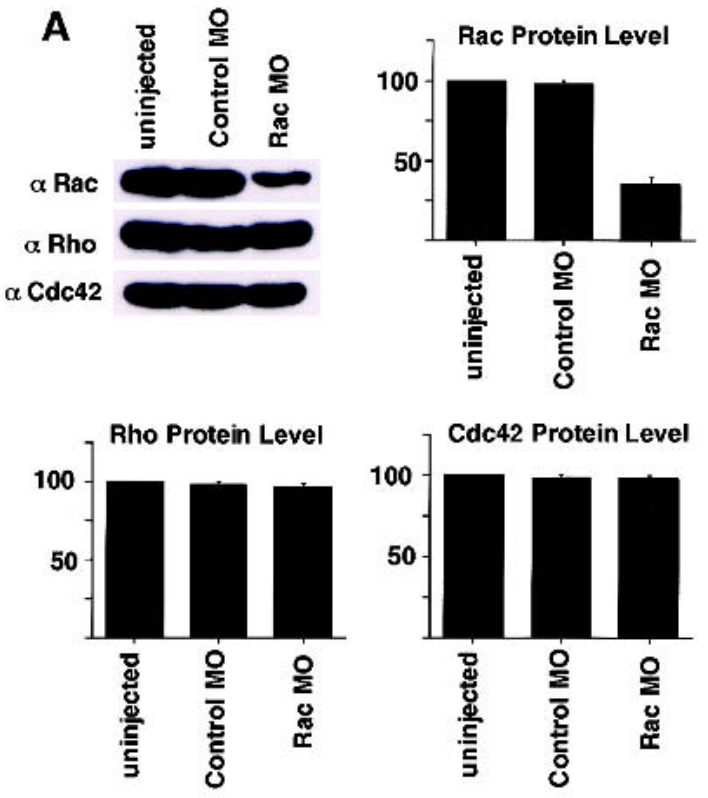

C

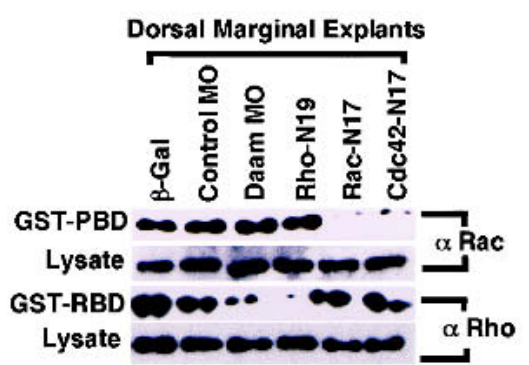

B
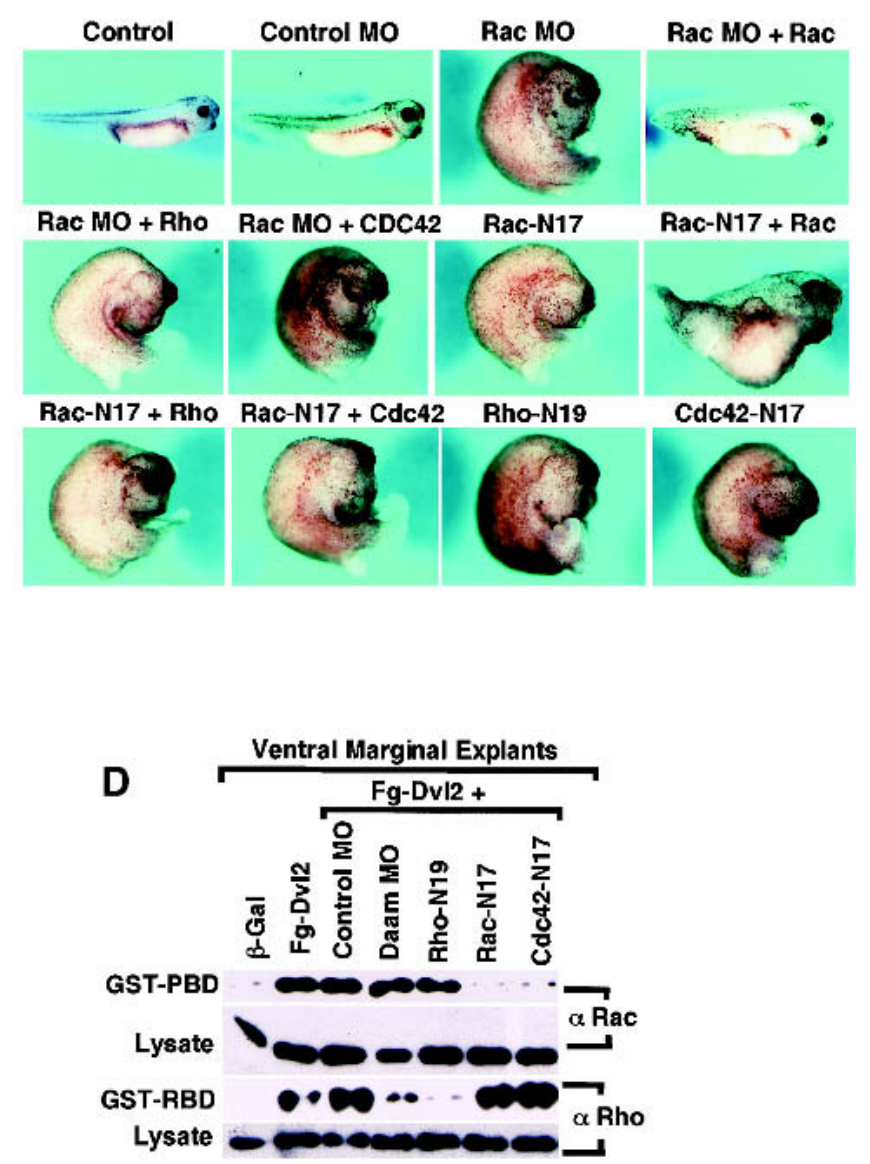

Figure 5. Rac function is required for Xenopus gastrulation. (A) XRac1 MO specifically reduced the protein level of endogenous Rac, but not Rho or Cdc42. A control MO had no effect on the level of any of these proteins. Fifty nanograms of the XRac1 MO or control $\mathrm{MO}$ was injected into 2-cell embryos, and whole embryo extracts were harvested at stage 10.5. (B) XRac1 MO, but not the control MO, and Rac-N17, Rho-N19, and Cdc42-N17 each inhibited gastrulation. The figure shows affected embryos in each case where a phenotype was seen; for frequency of effects, see Table 1. Fifty nanograms of either XRac1 MO or the control MO; 1 ng of RNA for Rac-N17, Rho-N19, or Cdc42-N17; or 2 ng of RNA for the wild-type Rac, Rho, or Cdc42 were each injected in the dorsal marginal region of the 4-cell-stage embryo, and resulting phenotypes were examined at stage 35. Injection of RNA ( 2 ng) for human Rac1, but not Rho or Cdc42, rescued the effect of the XRac1 MO, and had a weak ameliorating influence on the effect of Rac-N17. (C,D) Rho-N19 and Rac-N17 inhibited Rho and Rac activation, respectively. RNA (2 ng) or MO (50 ng) was injected at the 4-cell stage. (C) Dorsal injection, DMZ explants. Endogenous Rac activation was inhibited by RNA for Rac-N17 or Cdc42-N17 but not Rho-N19 or XDaam1 MO, whereas endogenous Rho activation was inhibited by Rho-N19 but not Rac-N17 or Cdc42-N17, and by XDaam1 MO but not the control MO. (D) Ventral injection, VMZ explants. Rac induction by Dv12 RNA was inhibited by coinjected RNA for Rac-N17 or Cdc42-N17 but not by Rho-N19 or XDaam1 MO, whereas Rho activation by Dv12 was suppressed by Rho-N19 but not Rac-N17 or Cdc42-N17, and by XDaam1 MO but not the control MO. 
Table 1. Rac is required for Xenopus gastrulation

\begin{tabular}{|c|c|c|c|c|}
\hline \multirow[b]{3}{*}{ Injection } & \multirow[b]{3}{*}{ Total } & \multicolumn{3}{|c|}{ Phenotype at stage 35} \\
\hline & & \multirow[b]{2}{*}{ Wild type (\%) } & \multicolumn{2}{|c|}{ Gastrulation defects } \\
\hline & & & $\begin{array}{c}\text { Severe } \\
(\%)\end{array}$ & $\begin{array}{l}\text { Intermediate } / \text { mild } \\
\qquad(\%)\end{array}$ \\
\hline Control (no injection) & 211 & 100 & 0 & 0 \\
\hline Control MO (50 ng) & 183 & 99 & 0 & 1 \\
\hline Rac MO (50 ng) & 174 & 68 & 12 & 20 \\
\hline $\mathrm{Rac} \mathrm{MO}+\mathrm{Rac} \mathrm{WT}(50+2 \mathrm{ng})$ & 67 & 90 & 4 & 6 \\
\hline Rac MO + Rho WT (50 + 2 ng) & 81 & 58 & 18 & 24 \\
\hline $\mathrm{Rac} \mathrm{MO}+\mathrm{Cdc} 42 \mathrm{WT}(50+2 \mathrm{ng})$ & 77 & 57 & 18 & 25 \\
\hline Rac N17 (1 ng) & 151 & 23 & 49 & 28 \\
\hline Rac N17 + Rac WT (1 + 2 ng) & 139 & 36 & 33 & 31 \\
\hline Rac N17 + Rho WT (1 + 2 ng) & 125 & 14 & 59 & 26 \\
\hline Rac N17 + Cdc42 WT (1 + 2 ng) & 122 & 11 & 63 & 26 \\
\hline Rac WT (2 ng) & 158 & 87 & 3 & 10 \\
\hline Rho WT (2 ng) & 158 & 84 & 3 & 13 \\
\hline Cdc42 WT (2 ng) & 154 & 85 & 3 & 12 \\
\hline Rho N19 (1 ng) & 141 & 29 & 54 & 21 \\
\hline Cdc42 N17 (1 ng) & 165 & 38 & 41 & 21 \\
\hline Cdc42 N17 + Cdc42 WT $(1+2 \mathrm{ng})$ & 111 & 47 & 23 & 30 \\
\hline Cdc42 N17 + Rac WT (1 + 2 ng) & 99 & 29 & 47 & 24 \\
\hline Cdc42 N17 + Rho WT (1 + 2 ng) & 105 & 22 & 45 & 33 \\
\hline
\end{tabular}

Embryos were injected dorsally at the 4-cell stage. Embryos with an open blastopore, exposed endodermal tissues and drastically reduced anterio-posterior (AP) axis were scored as severe gastrulation defects. Embryos with a small open blastopore or delayed blastopore closure, and a shortened AP axis or a bent body axis were scored as intermediate to mild gastrulation defects.

due to the residual XRacl protein or other Rac family members that were not affected by the MO. Indeed, the three known Rac genes in Drosophila have redundant functions during development (Hakeda-Suzuki et al. 2002). We thus examined the role of Rac (and other small GTPases) in Xenopus gastrulation via dominant interfering Rac-N17, Rho-N19, and Cdc42-N17 constructs, which in 293T cells exhibit specific inhibitory activities towards their cognate GTPases (Fig. 1D; Habas et al. 2001). In DMZ explants, where endogenous Rho and Rac are both activated, Rho-N19 inhibited Rho but not Rac activation, whereas Rac-N17 inhibited Rac but not Rho activation (Fig. 5C). Similarly in VMZ explants, where both Rho and Rac were activated by ectopic Dvl2, RhoN19 inhibited ectopic Rho but not Rac activation, whereas Rac-N17 inhibited ectopic Rac but not Rho activation (Fig. 5D). In Xenopus embryos, therefore, RhoN19 and Rac-N17 appear specific for Rho and Rac, most likely via titrating a Rho-GEF and a Rac-GEF, respectively. Different from results obtained in 293T cells, however, Cdc42-N17 interfered with the endogenous Rac (but not Rho) activation in the DMZ (Fig. 5C), and with ectopic Rac (but not Rho) activation induced by Dvl2 in the VMZ (Fig. 5D). One possibility is that Cdc42N17 cross-inhibits Rac by titrating the Rac-GEF in the embryo, as some GEFs can bind and activate both Cdc42 and Rac (for review, see Schmidt and Hall 2002). Alternatively, Cdc42 activation is upstream of Rac activation in the embryo (but not in 293T cells). We favor the former possibility, as we were unable to detect significant Cdc42 activation in Xenopus embryos, either en- dogenously or by ectopic Fz/Dvl signaling (Fig. 4B; data not shown).

Dorsal expression of Rac-N17 strongly inhibited Xenopus gastrulation (Fig. 5B; Table 1), again supporting a role for Rac in gastrulation. Coinjection of wild-type Rac RNA appeared to weakly rescue the effect of Rac-N17 in the embryo, but this rescue was not statistically significant (Fig. 5B; Table 1). This was not unexpected because Rac-N17, which has a higher affinity for GEFs than wildtype Rac, inhibits the nucleotide exchange step and thus Rac activation (Hart et al. 1994). Dorsal expression of Rho-N19 also inhibited Xenopus gastrulation (Fig. 5B; Table 1), consistent with previous observations (Wunnenberg-Stapleton et al. 1999; Habas et al. 2001). We further confirmed previous reports that Cdc42-N17 inhibits gastrulation (Fig. 5B; Table 1; Diiane et al. 2000; Choi and Han 2002).

\section{Rac function is required for convergent extension movements}

To further investigate the role of Rac in regulating CE movements, we examined the effect of XRac1 MO and Rac-N17 in animal explants, which upon activin treatment undergo morphogenetic elongation characteristic of CE movements in vivo (Symes and Smith 1987). Animal explants from embryos injected with the control MO showed normal elongation, but a significant portion of explants from embryos injected with the XRac1 MO did not (Fig. 6A; Table 2). The inhibitory effect of the XRac1 MO could be rescued by coinjection of RNA for 
A
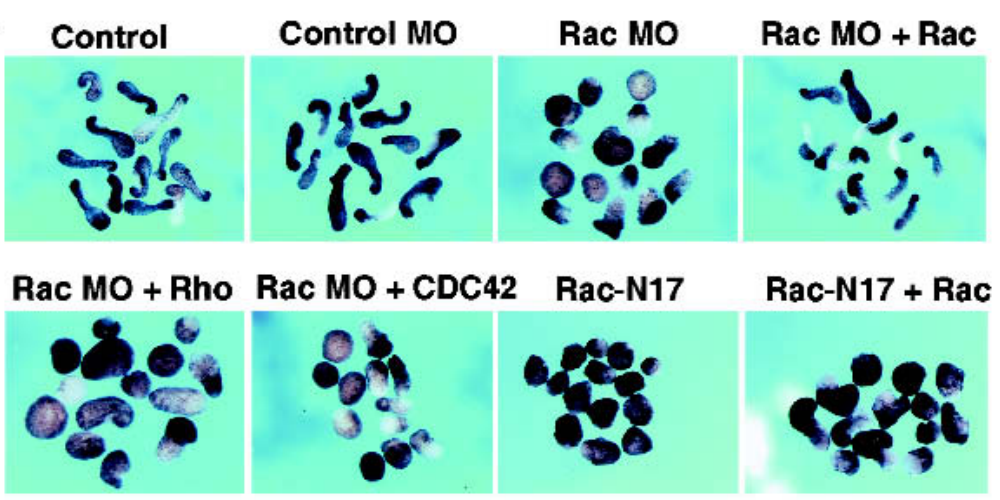

Rac-N17 + Rac
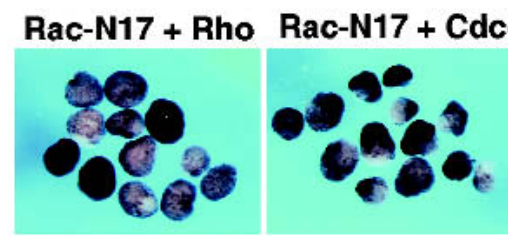

Rho-N19

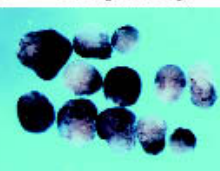

B
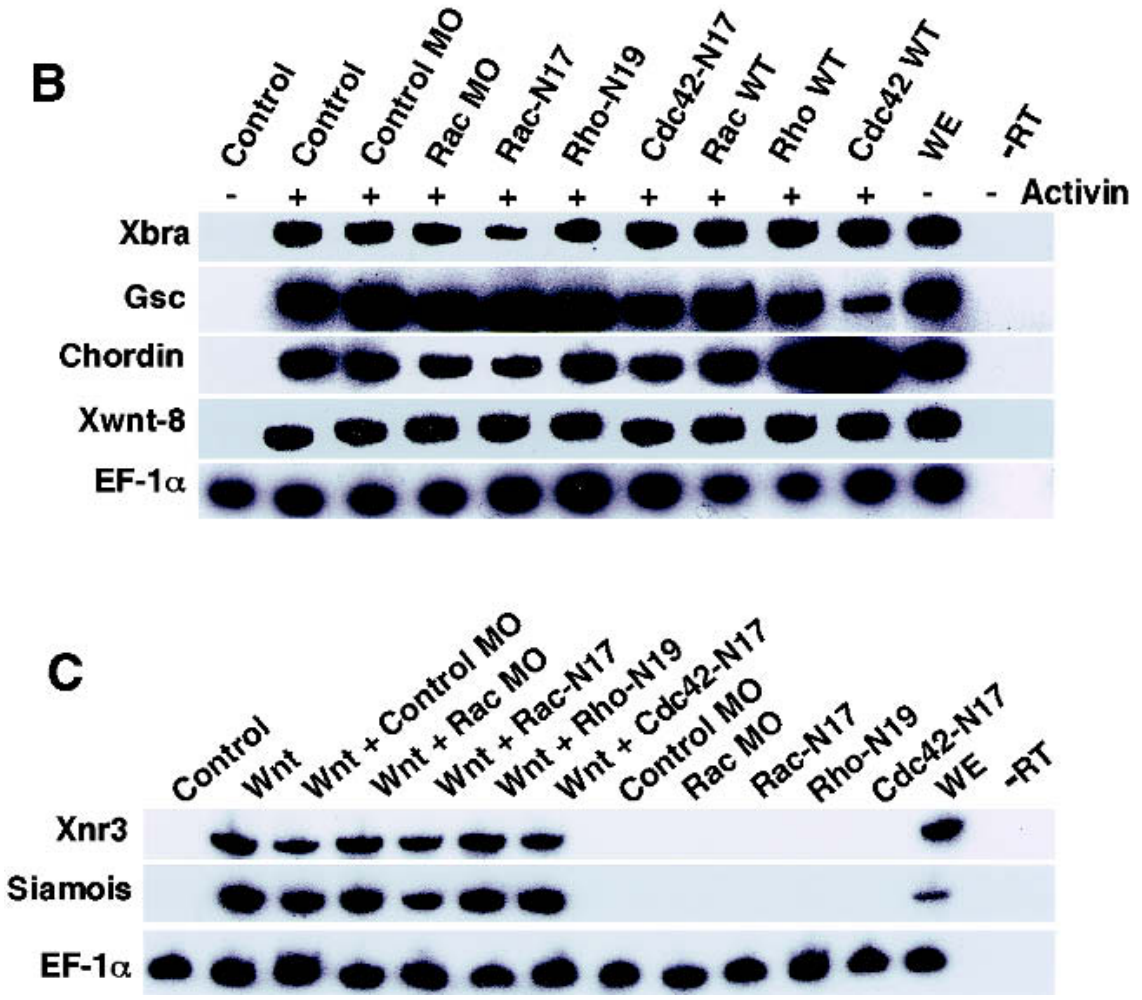

Figure 6. Rac function is required for convergent extension movements and is independent of the Wnt/ $\beta$-catenin pathway. (A) In animal explants treated with activin, XRacl MO but not the control MO (50 ng) inhibited elongation. RNA for human Rac1 (2 ng), but not Rho or Cdc42, rescued the XRacl MO effect. RNA (1 ng) for Rac-N17, Rho-N19, and Cdc42-N17 also inhibited convergent extension. The Rac-N17 effect was partially rescued by coinjected RNA (2 ng) for wild-type Rac, but not Rho or Cde42. $(B, C)$ In animal explants, neither XRacl MO nor dominant negative GTPase mutants affected mesodermal gene expression induced by activin $(B)$, or organizer markers induced by Xwnt8 RNA (20 pg; C), as assayed by RTPCR at stage 10.5. EF-1 $\alpha$ was used as an internal control. WE, whole embryo; - RT, no reverse transcriptase. human Rac1 but not for Rho or Cdc42. Expression of Rac-N17 also inhibited elongation, which was rescued partially by wild-type Rac but not by Rho or Cdc42 (Table 2). Thus both depletion and functional interference experiments suggest that Rac function is required for CE movements. In addition, Rho-N19, likely by interfering with Rho function downstream of Wnt-11/Fz signaling (Habas et al. 2001), inhibited elongation of animal pole explants; so did Cdc42-N17, as previously reported (Fig. 6A; Table 2; Djiane et al. 2000; Choi and Han
2002). Neither XRac1 MO nor any of the dominant mutant GTPases inhibited mesoderm gene expression in activin-treated explants, as assayed using a pan-mesodermal marker brachyury (Xbra), dorsal mesodermal markers goosecoid (gsc) and chordin, and ventrolateral mesodermal marker Xwnt8 (Fig. 6B). Thus depletion or inhibition of Rac and other GTPases perturbed morphogenetic movements without preventing mesoderm specification.

Finally, our observation that both Rac and Rho activa- 
Table 2. Rac is required for convergent extension movements

\begin{tabular}{|c|c|c|c|}
\hline \multirow[b]{2}{*}{ Injection } & \multirow[b]{2}{*}{$\begin{array}{l}\text { No. of } \\
\text { caps }\end{array}$} & \multicolumn{2}{|c|}{$\begin{array}{l}\text { Phenotype of } \\
\text { caps at stage } 17\end{array}$} \\
\hline & & $\begin{array}{c}\text { Elongation } \\
(\%)\end{array}$ & $\begin{array}{c}\text { No } \\
\text { elongation } \\
(\%)\end{array}$ \\
\hline Control (no injection) & 64 & 95 & 5 \\
\hline Control MO (50 ng) & 60 & 93 & 7 \\
\hline Rac MO (50 ng) & 70 & 57 & 43 \\
\hline $\begin{array}{l}\text { Rac MO + Rac WT } \\
\quad(50+2 \mathrm{ng})\end{array}$ & 66 & 91 & 9 \\
\hline $\begin{array}{l}\text { Rac MO + Rho WT } \\
(50+2 \mathrm{ng})\end{array}$ & 82 & 54 & 46 \\
\hline $\begin{array}{l}\text { Rac MO + Cdc42 WT } \\
\quad(50+2 \mathrm{ng})\end{array}$ & 116 & 56 & 44 \\
\hline Rac N17 (1 ng) & 66 & 11 & 89 \\
\hline $\begin{array}{l}\text { Rac N17 + Rac WT } \\
\quad(1+2 \mathrm{ng})\end{array}$ & 73 & 45 & 55 \\
\hline $\begin{array}{l}\text { Rac N17 + Rho WT } \\
\quad(1+2 \mathrm{ng})\end{array}$ & 59 & 14 & 86 \\
\hline $\begin{array}{l}\mathrm{Rac} \mathrm{N} 17+\mathrm{Cdc} 42 \mathrm{WT} \\
(1+2 \mathrm{ng})\end{array}$ & 67 & 7 & 93 \\
\hline Rho WT (2 ng) & 67 & 95 & 5 \\
\hline Rac WT (2 ng) & 64 & 94 & 6 \\
\hline Cdc42 WT (2 ng) & 64 & 92 & 8 \\
\hline Rho N19 (1 ng) & 61 & 10 & 90 \\
\hline Cdc42 N17 (1 ng) & 56 & 14 & 86 \\
\hline
\end{tabular}

Animal explants from injected embryos were cultured and treated with Activin, and their morphogenetic elongation was scored.

tion are downstream of Wnt/Fz signaling promoted us to evaluate the relationship between Rac and Rho and the well characterized Wnt/Fz/ $\beta$-catenin pathway, which in Xenopus embryos induces the expression of Xnr3 and Siamois and dorsal axis formation (Miller et al. 1999). Neither XRac1 MO nor any of the dominant interfering GTPases had any effect on Xwnt-8 induction of Xnr3 and Siamois in animal explants (Fig. 6C). In addition, these GTPase mutants did not block Xwnt- 8 induction of axis duplication, although the induced secondary axis was shortened and compressed, due presumably to defective morphogenetic movements (data not shown). These results support the notion that Wnt/Fz activation of Rac and Rho is independent of $\mathrm{Wnt} / \mathrm{Fz} / \beta$-catenin signaling.

\section{Discussion}

In this paper we provide evidence that in mammalian cells and Xenopus gastrulae, Wnt/Fz signaling activates both Rac and Rho GTPases in independent pathways downstream of Dvl, likely via inducing the formation of discrete Dvl-Rac and Dvl-Rho complexes. Interfering with either Rac or Rho activation perturbs Wnt/Fz regulation of Xenopus gastrulation. We propose that coactivation of Rac and Rho is a common feature of Wnt/Fz regulation of cell behavior.
Wnt/Fz activation of Rac and Rho via independent pathways downstream of Dvl

We previously demonstrated that Wnt/Fz signaling activates Rho (Habas et al. 2001). Our current study illustrates that Wnt/Fz signaling also activates Rac, and importantly, coactivates Rac and Rho in all cases examined. Two distinct Wnt molecules, Wnt-1 and XWnt-11, activate Rac and Rho in mammalian cells and Xenopus embryos. Wnt-1 activation of Rac and Rho is insensitive to inhibition of protein synthesis (Fig. 1B; Habas et al. 2001), indicating that Rac and Rho both lie directly downstream of Wnt signaling. During Xenopus gastrulation, Rac and Rho activation occurs in dorsal tissues where Wnt-11/Fz signaling is active, and is suppressed when Wnt-11/Fz signaling is inhibited (Fig. 4B-D). Although the faster kinetics of Rac activation in cultured cells (Fig. 1B; Habas et al. 2001) might imply that Wnt/Fz activates Rho though Rac, several lines of evidence argue for the existence of two independent pathways. Thus, Wnt/Fz activation of Rac and Rho is inhibited by RacN17 and Rho-N19, respectively (Figs. 1D, 5C,D; Habas et al. 2001), and requires different Dvl domains (Figs. 1C, 4C,D; Habas et al. 2001), and Rho but not Rac activation requires the Formin-homology protein Daam1 (Fig. 4C,D; Habas et al. 2001).

How does Wnt/Fz signaling via Dvl lead to Rac activation? One potential clue is that Wnt signaling induces complex formation between Dvl and Rac (Fig. 3A). The Dvl-Rac complex is observed with Dvl1 or Dvl2, either of which activates Rac, but not with Dvl3, which does not (Figs. 1C, 3A,C). In addition, the Dvl2 DEP domain is sufficient for Rac association and activation (Fig. 1C,D). Thus Dvl-Rac complex formation correlates with Rac activation by Wnt/Fz/Dvl. Consistent with independent Rac and Rho activation, Dvl-Rac and Dvl-Rho complexes are induced by Wnt independently, because the Dvl-Rho complex requires Daam1, whereas the Dvl-Rac complex does not (Fig. 3A; Habas et al. 2001).

Wnt/Fz activation of INK is mediated by Rac but not Rho activation

Although JNK has been implicated downstream of Wnt/ Fz/Dvl signaling via genetic and biochemical analyses (Boutros et al. 1998; Sun et al. 2001; Park and Moon 2002; Yamanaka et al. 2002), the relationship between JNK activation versus Rac and Rho activation was unknown. Consistent with reports regarding other signaling pathways showing that activated Rac (or Cdc42) but not Rho induces JNK activation (Coso et al. 1995; Minden et al. 1995), we find full correlation between activation of JNK and Rac but not Rho in the Wnt/Fz/Dvl signaling pathway. Thus, Rac and JNK activation is induced by Fz1 or Fz7 but weakly or not by Fz2 or Fz5, requires the Dvl DEP but not PDZ domain, is compromised in the Dsh ${ }^{1}$ mutant, and is blocked by Rac-N17 but not Rho-N19. Therefore, Wnt/Fz signaling diverges at the level of Dvl into a Rho and a Rac/JNK pathway.

Wnt-1 and Fz1, which are known for their roles in 
$\beta$-catenin signaling, also activate Rac/JNK and Rho (Figs. 1A,B, 2A,B; Habas et al. 2001). It is therefore worth considering whether some functions of Wnt-1, and possibly of other Wnts known to activate the canonical pathway, might be mediated by Rho and Rac in addition to $\beta$-catenin. For example, Wnt-1 transformation of mouse mammary epithelial cells is accompanied by morphological changes (Brown et al. 1986; Rijsewijk et al. 1987), which could be due to regulation of Rac and Rho activities. Genetic studies have implicated Wingless (Wnt-1), Rac, Rho, and JNK in Drosophila dorsal closure, a complex series of morphogenetic movements (Noselli 1998), and it has been suggested that Wingless may signal via both $\beta$-catenin and JNK to regulate this process (McEwen et al. 2000).

Rac and Rho are both required for Xenopus gastrulation

Wnt-11 is a key signaling molecule in Xenopus and zebrafish gastrulation, and is expressed in dorsal tissues where CE movements take place (Heisenberg et al. 2000; Tada and Smith 2000). A lack or inhibition of Wnt-11 function (Heisenberg et al. 2000; Tada and Smith 2000) or interference with $\mathrm{Fz}$ or Xdsh function causes defective CE movements (Deardorff et al. 1998; Djiane et al. 2000; Wallingford et al. 2000), and interference with Xdsh function disrupts cell polarization along the mediolateral axis, a pivotal step in CE movements (Wallingford et al. 2000). In support of these views, we find that Wnt$11 /$ Fz signaling and CE movements are accompanied by $\mathrm{Rac}$ and Rho activation on the dorsal but not ventral side of the Xenopus embryo (Fig. 4B-D).

Reduction of XRacl protein via a morpholino antisense oligonucleotide (MO) interferes with CE movements and gastrulation, which can be corrected by human Rac1 (Figs. 5B, 6A), suggesting that Rac activity is important for Xenopus gastrulation. Rac-N17 and RhoN19-which specifically inhibit Rac and Rho activation by Wnt-11 in Xenopus embryos, respectively (Figs. $5 \mathrm{C}, \mathrm{D})$-each result in severe defects in CE movements and gastrulation (Figs. 5B, 6A). While caution must be used when interpreting results obtained via dominant interfering GTPase mutants, these findings are consistent with those obtained from MO depletion experiments and support the model that Wnt-11/Fz/Dvl regulation of morphogenesis is achieved by parallel activation of both Rac and Rho. It is of interest to note that Xdd1 blocks Rho activation (Habas et al. 2001) but induces Rac activation (Fig. 4C,D), and is nonetheless a potent inhibitor of CE movements (Sokol 1996). We speculate that an imbalance of Rac and Rho activation is as detriment to cell polarity/movements as a lack of activation of either molecule. Detailed imaging analyses of Xenopus dorsal tissue during gastrulation suggest that Rho and Rac are required for elongated cell shape and filopodia formation, respectively (K. Symes, pers. comm.). Thus Wnt-11, by regulating Rho and Rac, may coordinate cell shape and filopodia formation during CE movements. We note that mouse embryos lacking rac1 gene die during gastrulation, and rac1-/- epiblast cells in culture exhibit defects in lamellipodia formation, cell adhesion, and movements (Sugihara et al. 1998).

Previous reports have suggested a role for Cdc42 in Xenopus morphogenesis, based in large part on the observation that Cdc42-N17 inhibits gastrulation (Djiane et al. 2000; Choi and Han 2002). We found that Cdc42N17 blocks Rac activation by Wnt-11/Dvl signaling in Xenopus embryos (Fig. 5C,D). As we do not detect Cdc42 activation by $\mathrm{Wnt} / \mathrm{Fz}$ signaling in mammalian cells or Xenopus embryos (Figs. 1B, 4B; Habas et al. 2001), and Cdc42 does not exhibit genetic interactions with DFz1/ Dsh in Drosophila (see below), we think that it is less likely but not entirely excluded that Cdc42 functions upstream of Rac in the Wnt-11 signaling pathway. Cdc42 may have a role in gastrulation by regulation of $\mathrm{Ca}^{2+}$ mediated cell adhesion as suggested (Winklbauer et al. 2001; Choi and Han 2002). However, we cannot rule out the possibility that Cdc42-N17 perturbs gastrulation, in part, by cross-inhibition of Rac activation.

\section{Rac and JNK: Similarities and distinctions between DFz1/Dsh Drosophila PCP function and Wnt-11/Fz signaling in Xenopus gastrulation}

Significant molecular similarities between DFz1/Dsh signaling in the establishment of Drosophila PCP and Wnt-11/Fz signaling in vertebrate gastrulation have been observed (Adler 2002; Wallingford et al. 2002). In addition to $\mathrm{Fz}$ and $\mathrm{Dsh} / \mathrm{Dvl}$, other gene products genetically defined as being critical for PCP, such as Rho, ROCK, and Strabismus, are also essential for vertebrate gastrulation (Wunnenberg-Stapleton et al. 1999; Habas et al. 2001; Darken et al. 2002; Goto and Keller 2002; Jessen et al. 2002; Park and Moon 2002; Marlow et al. 2002; the present work). Some genetic analyses have also implicated Rac and JNK in PCP function: (1) Rho-N19 and Rac-N17, and activated mutants of Rho and Rac, but not Cdc42-N17, each cause PCP abnormalities; (2) gene dosage reduction for $r h o A$, rac1 plus rac2, or for genes in the JNK signaling cassette (i.e., JNKK, JNK, JUN), but not for $c d c 42$, suppresses PCP defects caused by overexpression of DFzl or Dsh; (3) the PCP phenotype of $D f z 1$ or $d s h^{1}$ mutant can be rescued by overexpression of $r h o A$, rac1, or JNK cassette genes, but not by $c d c 42$ (Eaton et al. 1996; Strutt et al. 1997; Boutros et al. 1998; Fanto et al. 2000; for review, see Van Aelst and Symons 2002). These results suggest that Rac and JNK, like RhoA, may function downstream of Dsh, and in fact, Rac was suggested to act in parallel to, or upstream of, RhoA in Fz PCP signaling (Fanto et al. 2000). Observations that Wnt-11/ Fz signaling induces coactivation of Rac and Rho in parallel pathways downstream of Dvl, that Rac activation mediates Wnt/Fz activation of JNK, and that Rac and JNK are required for Xenopus gastrulation (Yamanaka et al. 2002; the present study), mirror the genetic analyses in Drosophila discussed above.

However, questions regarding a role for Rac and JNK signaling in PCP have been raised, because loss-of-function alleles for genes encoding JNKK, JNK, and JUN, and 
a triple deletion of the three known rac genes in Drosophila, rac1, rac2 and $m t 1$, fail to cause PCP defects (Adler 2002; Hakeda-Suzuki et al. 2002). We speculate that additional functional redundancy, or some difference between Fz signaling in Drosophila PCP and vertebrate gastrulation, may account for this discrepancy.

\section{Wnt/Fz/Dvl/Rac and Wnt/Fz/Dvl/Rho pathways}

Our studies together with genetic analyses in Drosophila have revealed two parallel pathways initiated by Wnt/Fz signaling in regulating cell polarity and movements: a Wnt/Fz/Dvl/Daam1/Rho/ROCK pathway and a Wnt/Fz/ $\mathrm{Dvl} / \mathrm{Rac} / \mathrm{JNK}$ pathway. A common Wnt/Fz/Dvl signaling cassette branches into these two pathways downstream of Dvl, most likely via distinct Dvl-Rac and DvlRho complexes (Fig. 7). The Rho/ROCK pathway regulates the phosphorylation of non-muscle myosin regulatory light chain and thus the assembly of actin filaments (Winter et al. 2001), whereas the Rac/JNK pathway may regulate cytoskeletal or nuclear events (Fanto et al. 2000; Das et al. 2002; but see Strutt et al. 2002). How coactivation of Rac and Rho pathways is translated into morphogenetic movements remains a future challenge.

\section{Materials and methods}

\section{Antibodies}

Monoclonal antibodies (mAbs) against HA (F-7), RhoA (26C4), Dvl1 (3f12), Dvl2 (10B5), Dvl3 (4D3), Myc (9E10), and P-c-Jun (KM-1) and polyclonal Abs (pAbs) against RhoA (119), c-Jun (H79), and Myc (N-262) were from Santa Cruz Biotechnology. mAbs against Rac and Cdc42 were from Transduction Labora-
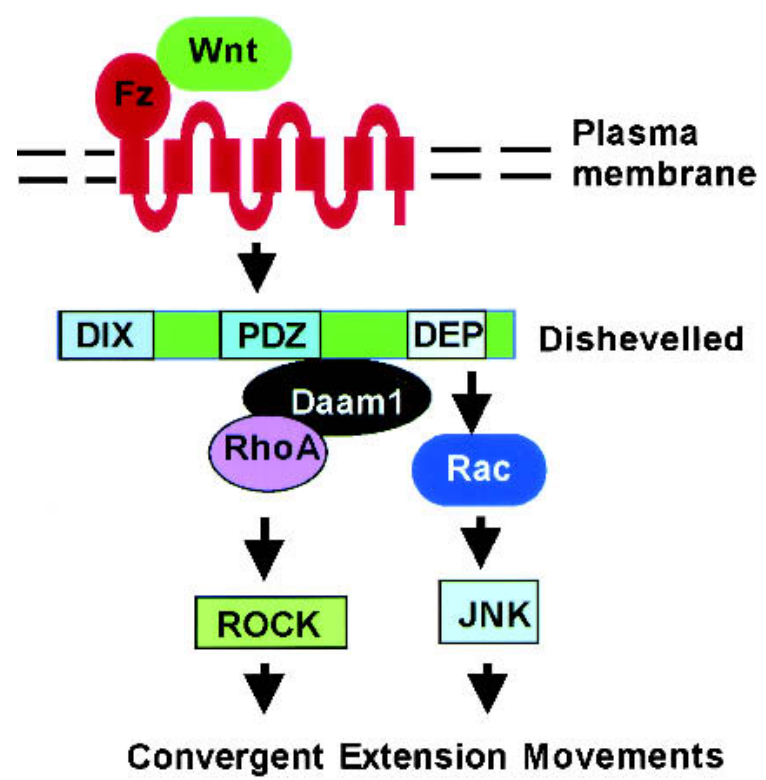

Figure 7. Parallel Rac and Rho pathways downstream of Wnt/ Fz/Dvl signaling (see Discussion). tories, and against Flag (M2) was from Sigma. pAbs against Dsh were kindly provided by Drs. R. Nusse and K. Willert.

\section{Plasmids and morpholino oligonucleotides}

The Frizzled, mouse Dvl2, Xdsh, and mutants were previously described (Habas et al. 2001). cDNAs for Mouse Dvll and Dvl3 were kindly provided by Dr. D. Sussman, and for Dsh and Dsh ${ }^{1}$ by Dr. M. Mlodzik. The Rho, Rac, Cdc42 and derived constructs were previously described (Sokol et al. 2001). The XRac1 MO designed to be complementary to the translational initiation site, 5'-GCCTGCATGGCAGCGAATGTCCCG-3', was synthesized by Gene Tools. An MO with a random sequence was used as the negative control.

\section{Cell transfection}

All cell transfections were done with HEK293T cells. Cells in a 6-well plate were transfected using the calcium phosphate method with $2 \mu \mathrm{g}$ of each indicated plasmid with the exception of Rho-N19, Rac-N17, and Cdc42-N17 (3 $\mu$ g each). Transfected DNA amounts were equalized via vectors without inserts.

\section{Rho, Rac, and Cdc42 activation assays}

For Rac/Cdc42 assays, cells were incubated in $0.5 \%$ serum $6 \mathrm{~h}$ prior to transfection, maintained in this serum concentration after transfection, and lysed $36 \mathrm{~h}$ posttransfection in the lysis buffer for Rac/Cdc42 (Benard et al. 1999). For Rho assays, the cells were maintained in $10 \%$ serum pre- and posttransfection and lysed $36 \mathrm{~h}$ posttransfection in Rho lysis buffer (Ren et al. 1999). Xenopus DMZ or VMZ was dissected at stage 10.5 and lysed in the Rho or Rac lysis buffer. GST-RBD and GST-PBD binding assays were performed as described (Benard et al. 1999; Ren et al. 1999|, and samples were resolved by $12 \%$ SDS-PAGE and immunoblotted with the anti-Rho, anti-Rac, or anti-Cdc42 $\mathrm{mAb}$ for cell lysates and anti-Rho pAB or anti-Rac and antiCdc42 mAbs for Xenopus explants. Protein expression levels from transfected cDNA plasmids were monitored by anti-HA, anti-Flag (Fg), anti-Myc, anti-Dvl1, anti-Dvl2, anti-Dvl3, or Dsh Abs. Cycloheximide was added at a final concentration of 10 $\mu \mathrm{g} / \mathrm{mL}$, starting $1 \mathrm{~h}$ prior to Wnt-1 CM treatment.

\section{JNK assays}

For JNK assays, cells were incubated in $0.5 \%$ serum $6 \mathrm{~h}$ prior to transfection, maintained in this serum concentration after transfection, and lysed $36 \mathrm{~h}$ posttransfection in $0.5 \%$ NP40 lysis buffer. Samples were resolved on $12 \%$ SDS-PAGE and immunoblotted with anti-P-c-JNK (for phosphoserine 63), anti-Myc, anti-Flag, anti-HA, anti-Dvl-1, anti-Dvl-2, or anti-Dvl-3 mAbs or anti-c-Jun pAb.

\section{Immunoprecipitation and immunoblotting}

Cells were lysed $36 \mathrm{~h}$ posttransfection in the Rho lysis buffer for $\mathrm{Dvl} / \mathrm{Rho} / \mathrm{Rac}$ complex detection. The protein level of endogenous RhoA, Rac, and Cdc42, of transfected Fz, Dvl2, Xdsh, Dsh, Daam1, and their mutants was examined via blotting the cell lysate with indicated Abs. For Dvl-Rac or Dvl-Rho complex detection, lysates were precipitated with anti-Rho, antiRac, anti-Cdc42 (mAbs), resolved by $12 \%$ SDS-PAGE, and blotted with anti-Dvl1, anti-Dvl2, anti-Dvl3, anti-Rho, anti-Rac, or anti-Cdc42 mAb. Detection was performed with SuperSignal WestPico (Pierce). 
Embryo manipulations, $R T-P C R$, and explant assays

These were performed as described (Kato et al. 1999; Habas et al. 2001). Embryo injections were done with in vitro transcribed RNAs. Convergent extension assays in explants were performed as described (Sokol 1996) using $5 \mathrm{ng} / \mathrm{mL}$ activin (final).

\section{Acknowledgments}

We thank M. Greenberg, A. Hall, M. Lin, M. Mlodzik, R. Nusse, M. Semenov, S. Shamah, D.L. Shi, J.C. Smith, D. Slack, S. Sokol, D. Sussman, M. Tada, K. Tolias, K. Willert, and Y. Zheng for reagents; Christopher Cox and K. Tolias for advice; K. Symes for communications; and Y. Kato, M. Tsang, N. Hukreide, and members of the Dawid and He labs for comments and stimulating discussion. This work is in part supported by a postdoctoral fellowship from NIH (NS07473) to R.H., and grants from NIH and DOD to X.H., who is a Pew Scholar, Klingenstein Fellow, and Keck Foundation Distinguished Young Scholar.

The publication costs of this article were defrayed in part by payment of page charges. This article must therefore be hereby marked "advertisement" in accordance with 18 USC section 1734 solely to indicate this fact.

\section{References}

Adler, P.N. 2002. Planar signaling and morphogenesis in Drosophila. Dev. Cell. 2: 525-535.

Akasaki, T., Koga, H., and Sumimoto, H. 1999. Phosphoinositide 3-kinase-dependent and -independent activation of the small GTPase Rac2 in human neutrophils. J. Biol. Chem. 274: 18055-18059.

Axelrod, J.D. 2001. Unipolar membrane association of Dishevelled mediates Frizzled planar cell polarity signaling. Genes \& Dev. 15: 1182-1187.

Axelrod, J.D., Miller, J.R., Shulman, J.M., Moon, R.T., and Perrimon, N. 1998. Differential recruitment of Dishevelled provides signaling specificity in the planar cell polarity and Wingless signaling pathways. Genes \& Dev. 12: 2610-2622.

Benard, V., Bohl, B.P., and Bokoch, G.M. 1999. Characterization of Rac and Cdc42 activation in chemoattractant-stimulated human neutrophils using a novel assay for active GTPases. J. Biol. Chem. 274: 13198-13204.

Boutros, M. and Mlodzik, M. 1999. Dishevelled: At the crossroads of divergent intracellular signaling pathways. Mech. Dev. 83: 27-37.

Boutros, M., Paricio, N., Strutt, D.I., and Mlodzik, M. 1998. Dishevelled activates JNK and discriminates between JNK pathways in planar polarity and wingless signaling. Cell 94: 109-118.

Brown, A.M., Wildin, R.S., Prendergast, T.J., and Varmus, H.E. 1986. A retrovirus vector expressing the putative mammary oncogene int-1 causes partial transformation of a mammary epithelial cell line. Cell 46: 1001-1009.

Choi, S. and Han, J. 2002. Xenopus Cdc42 regulates convergent extension movements during gastrulation through Wnt/ $\mathrm{Ca}^{2+}$ signaling pathway. Dev. Bio. 244: 342-357.

Coso, O.A., Chiariello, M., Yu, J.C., Teramoto, H., Crespo, P., $\mathrm{Xu}$, N., Miki, T., and Gutkind, J.S. 1995. The small GTPbinding proteins Rac1 and Cdc42 regulate the activity of the JNK/SAPK signaling pathway. Cell 81: 1137-1146.
Darken, R.S., Scola, A.M., Rakeman, A.S., Das, G., Mlodzik, M., and Wilson, P.A. 2002. The planar polarity gene strabismus regulates convergent extension movements in Xenopus. EMBO I. 21: 976-985.

Das, G., Reynolds-Kenneally, J., and Mlodzik, M. 2002. The atypical cadherin Flamingo links Frizzled and Notch signaling in planar polarity establishment in the Drosophila eye. Dev. Cell. 2: 655-666.

Deardorff, M.A., Tan, C., Conrad, L.J., and Klein, P.S. 1998. Frizzled- 8 is expressed in the Spemann organizer and plays a role in early morphogenesis. Development 125: 2687-2700.

Djiane, A., Riou, J.F., Umbhauer, M., Boucaut, J.C., and Shi, D.L. 2000. Role of Frizzled7 in the regulation of convergent extension movements during gastrulation in Xenopus laevis. Development 127: 3091-3400.

Eaton, S., Wepf, R., and Simons, K. 1996. Roles of Rac1 and Cdc42 in planar polarization and hair outgrowth in the wing of Drosophila. J. Cell Biol. 135: 1277-1289.

Fanto, M., Weber, U., Strutt, D. I., and Mlodzik, M. 2000. Nuclear signaling by Rac and Rho GTPases is required in the establishment of epithelial planar polarity in the Drosophila eye. Curr. Biol. 10: 979-988.

Goto, T. and Keller, R. 2002. The planar cell polarity gene strabismus regulates convergence and extension and neural fold closure in Xenopus. Dev Biol. 247: 165-181.

Habas, R., Kato, Y., and He, X. 2001. Wnt/Frizzled activation of Rho regulates vertebrate gastrulation and requires a novel Formin homology protein Daam1. Cell 107: 843-854.

Hakeda-Suzuki, S., Ng, J., Tzu, J., Dietzl, G., Sun, Y., Harms, M., Nardine, T., Luo, L., and Dickson, B.J. 2002. Rac function and regulation during Drosophila development. Nature 416: 438-442.

Hall, A. 1998. Rho GTPases and the actin cytoskeleton. Science 279: 509-514.

Hart, M, Eva, A., Zangrilli, D., Aaronson, S., Evens, T., Cerione, R., and Zheng, Y. 1994. Cellular transformation and guanine nucleotide exchange activity are catalyzed by a common domain on the dbl oncogene product. J. Biol. Chem. 269: 6265.

He, X., Saint-Jeannet, J.P., Wang, Y., Nathans, J., Dawid, I., and Varmus, H. 1997. A member of the Frizzled protein family mediating axis induction by Wnt-5A. Science 275: 1652-1654.

Heisenberg, C.P., Tada, M., Rauch, G.J., Saude, L., Concha, M.L., Geisler, R., Stemple, D.L., Smith, J.C., and Wilson, S.W. 2000. Silberblick/Wnt11 mediates convergent extension movements during zebrafish gastrulation. Nature 405: 76-81.

Jessen, J.R., Topczewski, J., Bingham, S., Sepich, D.S., Marlow, F., Chandrasekhar, A., and Solnica-Krezel, L. 2002. Zebrafish trilobite identifies new roles for Strabismus in gastrulation and neuronal movements. Nat Cell Biol. 4: 610-615.

Kaibuchi, K., Kuroda, S., and Amano, M. 1999. Regulation of the cytoskeleton and cell adhesion by the Rho family GTPases in mammalian cells. Annu. Rev. Biochem. 68: 459-486.

Kato, Y., Shi, Y., and He, X. 1999. Neuralization of the Xenopus embryo by inhibition of p300/CREB-binding protein function. J. Neuroscience. 19: 9364-9373.

Li, L., Yuan, H., Xie, W., Mao, J., Caruso, A.M., McMahon, A.P., Sussman, D.J., and Wu, D. 1999. Dishevelled proteins lead to two signaling pathways. Regulation of LEF-1 and c-Jun Nterminal kinase in mammalian cells. J. Biol. Chem. 274: 129-134.

Lisovsky, M., Itoh, K., and Sokol, S.Y. 2002. Frizzled receptors activate a novel JNK-dependent pathway that may lead to apoptosis. Curr Biol. 12: 53-58. 
Lucas, J, M., Nikolic, I., and Hens, M.D. 2002. cDNA cloning, sequence comparison, and developmental expression of Xenopus rac1. Mech Dev. 115: 113-116.

Marlow, F., Topczewski, J., Sepich, D., Solnica-Krezel, L. 2002. Zebrafish rho kinase 2 acts downstream of wnt1 1 to mediate cell polarity and effective convergence and extension movements. Curr Biol. 12: 876-884.

McEwen, D.G., Cox, R.T., and Peifer, M. 2000. The canonical Wg and JNK signaling cascades collaborate to promote both dorsal closure and ventral patterning. Development 127: 3607-3617.

Medina, A., Reintsch, W., and Steinbeisser, H. 2000. Xenopus Frizzled 7 can act in canonical and non-canonical Wnt signaling pathways; implications on early patterning and morphogenesis. Mech. Dev. 92: 227-237.

Miller, J.R., Hocking, A.M., Brown, J.D., and Moon, R.T. 1999. Mechanism and function of signal transduction by the Wnt/ beta-catenin and Wnt/Ca2+ pathways. Oncogene 18: 7860 7872.

Minden, A., Lin, A., Claret, F.X., Abo, A., and Karin, M. 1995. Selective activation of the JNK signaling cascade and c-Jun transcriptional activity by the small GTPases Rac and Cdc42Hs. Cell 81: 1147-1157.

Mlodzik, M. 1999. Planar polarity in the Drosophila eye: a multifaceted view of signaling specificity and cross talk. EMBO J. 18: 6873-6879.

Moriguchi, T., Kawachi, K., Kamakura, S., Masuyama, N., Yamanaka, H., Matsumoto, K., Kikuchi, A., and Nishida, E. 1999. Distinct domains of mouse dishevelled are responsible for the c-Jun N-terminal kinase/stress-activated protein kinase activation and the axis formation in vertebrates. I Biol. Chem. 274: 30957-30962.

Noselli, S. 1998. JNK signaling and morphogenesis in Drosophila. Trends Genet. 14: 33-38.

Park, M. and Moon, R.T. 2002. The planar cell-polarity gene stbm regulates cell behaviour and cell fate in vertebrate embryos. Nat. Cell Biol. 4: 20-25.

Pinson, K.I., Brennan, J., Monkley, S., Avery, B.J., and Skarnes, W.C. 2000. An LDL-receptor-related protein mediates Wnt signaling in mice. Nature 407: 535-538.

Ren, X.D., Kiosses, W.B., and Schwartz, M.A. 1999. Regulation of the small GTP-binding protein Rho by cell adhesion and the cytoskeleton. EMBO J. 18: 578-585.

Rijsewijk, F., van Deemter, L., Wagenaar, E., Sonnenberg, A., and Nusse, R. 1987. Transfection of the int-1 mammary oncogene in cuboidal RAC mammary cell line results in morphological transformation and tumorigenicity. EMBO J. 6: $127-131$.

Schmidt, A. and Hall, A. 2002. Guanine nucleotide exchange factors for Rho GTPases: Turning on the switch. Genes \& Dev. 16: 1587-1609.

Shamah, S.H., Lin, M.Z., Goldberg, J.L., Estrach, S., Sahin, M., Hu, L., Bazalakova, M., Neve, R.L., Corfas, G., Debant, A., et al. 2001. EphA receptors regulate growth cone dynamics through the novel guanine exchange factor Ephexin. Cell 105: 233-244.

Sheldahl, L.C., Park, M., Malbon, C.C., and Moon, R.T. 1999. Protein kinase $\mathrm{C}$ is differentially stimulated by Wnt and Frizzled homologs in a G-protein-dependent manner. Curr. Biol. 9: 695-698.

Shih, J. and Keller, R. 1992. Patterns of cell motility in the organizer and dorsal mesoderm of Xenopus laevis. Development 116: 915-930.

Shulman, J.M., Perrimon, N., and Axelrod, J.D. 1998. Frizzled signaling and the developmental control of cell polarity. Trends Genet. 14: 452-458.
Sokol, S.Y. 1996. Analysis of Dishevelled signaling pathways during Xenopus development. Curr. Biol. 6: 1456-1467.

Sokol, S.Y., Li, Z., Sacks, D.B. 2001. The effect of IQGAP1 on Xenopus embryonic ectoderm requires Cdc42. J. Biol. Chem. 276: 48425-48430.

Strutt, D.I. 2001. Asymmetric localization of frizzled and the establishment of cell polarity in the Drosophila wing. Mol Cell. 7: 367-375.

Strutt, D.I., Weber, U., and Mlodzik, M. 1997. The role of RhoA in tissue polarity and Frizzled signaling. Nature 387: 292295.

Strutt, D., Johnson, R., Cooper, K., and Bray, S. 2002. Asymmetric localization of frizzled and the determination of notchdependent cell fate in the Drosophila eye. Curr. Biol. 12: $813-824$.

Sugihara, K., Nakatsuji, N., Nakamura, K., Nakao, K., Hashimoto, R., Otani, H., Sakagami, H., Kondo, H., Nozawa, S., Aiba, A., et al. 1998. Racl is required for the formation of three germ layers during gastrulation. Oncogene 17: 34273433.

Sumanas, S., Strege, P., Heasman, J., and Ekker, S.C. 2000. The putative Wnt receptor Xenopus frizzled-7 functions upstream of $\beta$-catenin in vertebrate dorsoventral mesoderm patterning. Development 127: 1981-1990.

Sun, T.Q., Lu, B., Feng, J.J., Reinhard, C., Jan, Y.N., Fantl, W.J., Williams, L.T. 2001. PAR-1 is a Dishevelled-associated kinase and a positive regulator of Wnt signaling. Nat Cell Biol. 3: 628-636.

Symes, K. and Smith, J.C. 1987. Gastrulation movements provide an early marker of mesoderm induction in Xenopus laevis. Development 101: 339-349.

Tada, M. and Smith, J.C. 2000. Xwnt11 is a target of Xenopus brachyury: Regulation of gastrulation movements via $\mathrm{Di}$ shevelled, but not through the canonical Wnt pathway. Development 127: 2227-2238.

Tamai, K., Semenov, M., Kato, Y., Spokony, R., Liu, C., Katsuyama, Y., Hess, F., Saint-Jeannet, J.P., and He, X. 2000. LDL-receptor-related proteins in Wnt signal transduction. Nature. 407: 530-535.

Tree, D.R.P., Shulman, J.M., Rousset, R., Scott, M.P., Gubb, D., and Axelrod, J.D. 2002. Prickle mediates feedback amplification to generate asymmetric planar polarity signaling. Cell 109: 371-381.

Usui, T., Shima, Y., Shimada, Y., Hirano, S., Burgess, R.W., Schwarz, T.L., Takeichi, M., and Uemura. T. 1999. Flamingo, a seven-pass transmembrane cadherin, regulates planar cell polarity under the control of Frizzled. Cell 98: 585595.

Van, Aelst. L. and Symons, M. 2002. Role of Rho family GTPases in epithelial morphogenesis. Genes \& Dev. 16: 1032-1054.

Wallingford, J.B., Rowning, B.A., Vogeli, K., M., Rothbacher, U., Fraser, S.E., and Harland, R.M. 2000. Dishevelled controls cell polarity during Xenopus gastrulation. Nature 404: $81-$ 85.

Wallingford, J.B., Fraser, S.E., and Harland, R.M. 2002. Convergent extension: The molecular control of polarized cell movement during embryonic development. Dev. Cell. 6: 695-706.

Wehrli, M., Dougan, S.T., Caldwell, K., O’Keefe, L., Schwartz, S., Vaizel-Ohayon, D., Schejter, E., Tomlinson, A., and DiNardo, S. 2000. arrow encodes an Ldl-receptor-related protein essential for Wingless signaling. Nature 407: $527-530$.

Winklbauer, R., Medina, A., Swain, R.K., and Steinbeisser, H. 2001. Frizzled-7 signalling controls tissue separation during 
Xenopus gastrulation. Nature 413: 856-860.

Winter, C.G., Wang, B., Ballew, A., Royou, A., Karess, R., Axelrod, J.D., and Luo, L. 2001. Drosophila Rho-associated kinase (Drok) links Frizzled-mediated planar cell polarity signaling to the actin cytoskeleton. Cell 105: 81-91.

Wodarz, A. and Nusse, R. 1998. Mechanisms of Wnt signaling in development. Annu. Rev. Cell Dev. Biol. 14: 59-88.

Wolff, T. and Rubin, G.M. 1998. Strabismus, a novel gene that regulates tissue polarity and cell fate decisions in Drosophila. Development 125: 1149-1159.

Wunnenberg-Stapleton, K., Blitz, I.L., Hashimoto, C., and Cho, K.W. 1999. Involvement of the small GTPases XRhoA and XRnd 1 in cell adhesion and head formation in early Xenopus development. Development 126: 5339-5351.

Yamanaka, H., Moriguchi, T., Masuyama, N., Kusakabe, M., Hanafusa, H., Takada, R., Takada, S., and Nishida, E. 2002. JNK functions in the non-canonical Wnt pathway to regulate convergent extension movements in vertebrates. EMBO Rep. 3: 69-75.

Yang-Snyder, J., Miller, J.R., Brown, J.D., Lai, C-J., and Moon, R.T. 1996. A Frizzled homolog functions in a vertebrate Wnt signaling pathway. Curr. Biol. 6: 1302-1306. 


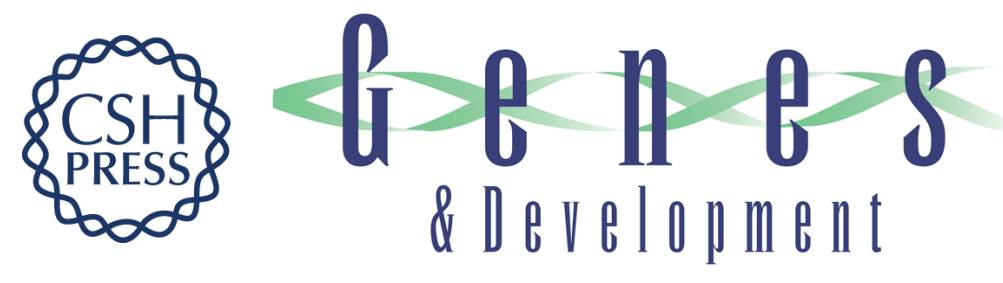

\section{Coactivation of Rac and Rho by Wnt/Frizzled signaling is required for vertebrate gastrulation}

Raymond Habas, Igor B. Dawid and Xi He

Genes Dev. 2003, 17:

Access the most recent version at doi:10.1101/gad.1022203

References This article cites 69 articles, 27 of which can be accessed free at: http://genesdev.cshlp.org/content/17/2/295.full.html\#ref-list-1

License

Email Alerting

Receive free email alerts when new articles cite this article - sign up in the box at the top Service right corner of the article or click here.

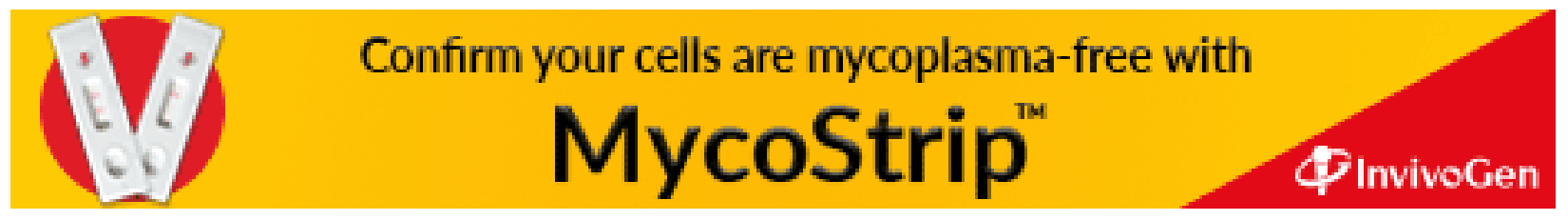

